\title{
Energy-Efficiency Economics as a Resource for Energy Planning
}

\author{
Fabio Correa Leite, Decio Cicone Jr., \\ Luiz Claudio Ribeiro Galvão, Miguel Edgar Morales Udaeta \\ Energy Group of Electric Energy and Automation Engineering Department, \\ Polytechnic School, University of São Paulo, São Paulo, Brazil \\ Email: udaeta@pea.usp.br, udaeta@iee.usp.br
}

Received January 14, 2013; revised February 15, 2013; accepted March 7, 2013

\begin{abstract}
The objective of this work is a multi-criteria decision-making assessment that aims to facilitate the Energy-Efficiency Economics, introducing the Analytic Hierarchy Process (AHP) as part of power-system planning tool for an energyefficiency application. It addresses to include qualitative aspects in the decision-making agendas of energy-efficiency projects. The manuscript details the limitations of non-rigorous financial analysis and proposes an alternative for including energy-efficiency measures in discussions pertaining to the financial opportunities available to any investor, and it presents the methodology that supports the qualitative aspects and the software package used to execute this methodology. As case study a complete example including a sensitivity analysis is presented.
\end{abstract}

Keywords: Energy Conservation; Energy Planning; Power Economics; Analytic Hierarchy Process (AHP)

\section{Introduction}

Energy-efficiency projects analyzed exclusively from the managerial perspective tend to make these projects less attractive once their hard benefits that are not trivial to quantify. Energy that is not spent is particularly difficult to measure and investors require a wide range of information to decide where to invest his capital and longterm benefits are not always represented in the financial indicators. "The acquisition of resources for investment is often limited, and managers tend to favor a company's core business while deteriorating secondary functions, including energy" [1].

Medium and large companies not rarely have mission statements that can be as vague as: operate safely, respect the environment and increase shareholder value. This is their way to communicate to the employees, company's owners and society what drives their goals. Meanwhile, investment decisions are still based on traditional methods and a subjective ingredient: the decision maker's own beliefs. From that perspective, how does a company decide between its environmental footprint or a more attractive IRR? It is a challenging decision because projects can fulfill regulations and industry standards and still impact the society in different ways. Regulations are not perfect, and one project is supposedly less harmless to the environment than the other. Then the question is: how to translate business major subjective goals into an organized and repeatable decision-making process?

Project managers, capital leaders and engineering managers have to make project decisions all the time. Some decisions are as comprehensive as whether to build a LEED office building or an ordinary one. This could never happen without committed leadership on the part of the organization. Or the simple choice of a high-efficiency motor rather than a standard one involves an additional capital investment, which, if not supported by top management, can lead to unpleasant disputes.

The consideration of non-monetary aspects in an investment decision through AHP is a possibility to help decision-makers choose energy-efficient and environmentally friendly projects through a standardized process. In this sense, it is proposed a way of analyzing energyefficiency projects in terms of similar parameters to any other expansion, acquisition or fusion project, including, in addition, elements that are not part of the traditional decision-making process, such as qualitative factors used in the AHP.

This article aims to discuss certain specifics, which, when added to well-known methods of financial analysis like Net Present Value (NPV) and Internal Rate of Return (IRR), make energy-efficiency projects more attractive from the financial perspective and an alternative way to base decisions with a more comprehensive approach. Accordingly, it quantifies qualitative aspects by considering them in the decision-making process. 


\section{Features of Energy Efficiency Economics}

Industries that make intensive use of utilities (electricity, industrial water, vapor, cooled water, etc.) are, in their majority, capital-intensive industries. The growth process of capital-intensive industries requires large investments; on the other hand, long-term bank credit for these companies is limited, and thus, companies can opt to go public as an alternative for fund raising. Therefore, low investment returns must be compensated by solid profit margins in order to attract investors.

Typical shareholders are not willing to use a part of their resources to generate a capital reserve for energy projects. Investors study any investment from the standpoint of a risk-return relationship, in any type of project. They attribute energy-efficiency applications with the same level of importance as new product projects and expansions, for instance, in decision-making processes.

Therefore, there is the need to show investors why they should invest in a project that might save some thousands of dollars in electricity compared to a project that would increase sales, the company's working capital and consequently the profits.

\subsection{Economics of Project}

There are several well-known methodologies for project analysis and investors are used to following only a few parameters that support comparisons between projects. The most popular methods are simple payback and discounted cash flow analysis.

To illustrate an example of the different perspective between the traditional and multivariate project decisionmaking processes, a US $\$ 60,000$ project is presented to improve a condensate return system in the manufacturing area, including a new high-pressure condensate flash tank with controls to capture low-pressure flash steam, a new condensate return pumping system, and the stan- dardization of steam traps.

This project could save US $\$ 30,000 /$ year in energy due to increased condensate return and recovery of flash steam, reduce fixed-cost savings by US $\$ 3000$ through the standardization of parts. However, variable maintenance costs would be increased by US $\$ 7000$, due to new sophisticated equipment. Reference [2] indicated that over the next few years, the cost of energy is expected to rise faster than other costs. Inflation in Brazil is projected to keep hovering at around $4.5 \% / \mathrm{yr}$; accordingly, maintenance- and fixed-cost inflation was set at $4 \% / \mathrm{yr}$ and energy inflation at 5\%/yr.

According to Brazilian regulations, this kind of investment must be equally depreciated in 10 years, resulting in a US $\$ 6000 /$ year cost with depreciation. Taking all of these considerations in account results in the following cash flow data (see Table 1).

The NPV (Net Present Value), calculated from the PTOI (Pre-Tax Operating Income) net savings, is 52,500 US dollars for an IRR of $47 \%$. Since the NPV is positive and the IRR is greater than the discount rate, this means that the project creates the amount of 52,500 US dollars over 10 years, as long as we only consider the cash flow from the estimated savings and expenses. On the other hand, it is necessary to remember that the calculation of NPV from the estimated savings minus the expenses is not the actual amount created for the investor. The depreciation of the assets and the additional taxes paid have to be included. Therefore, it is necessary to include these two items in the NPV calculation. In Brazil, the tax system is complex; the total amount of taxes paid in 2008 was about $35 \%$ of Gross Domestic Product (GDP) [3]. For the purposes of simplification, in this calculation the fraction considered as tax is $30 \%$. Therefore, the new calculation, including depreciation and taxes, gives us an NPV of 28,000 US dollars and an IRR of $36 \%$. It means

Table 1. Cash flow aimed at the improvement of the condensate system.

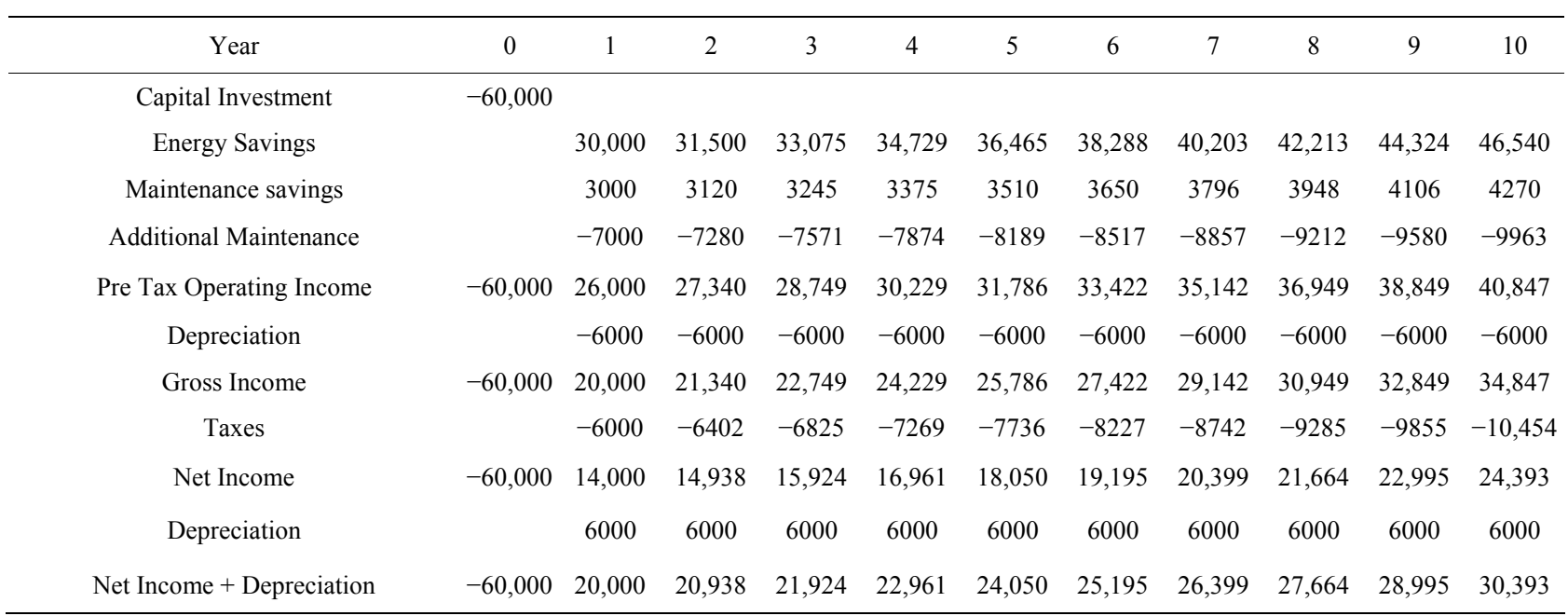


$43 \%$ lower financial attractiveness. Indeed, the financial attractiveness is not actually smaller, only more realistic from the investor's standpoint.

\section{Decision Making for Sustainable Energy}

Most of the time, only immediate monetary aspects are considered in energy-efficiency projects, although quailtative aspects can be quantified and considered in the decision-making process. That is very important when looking for more expressiveness in energy planning, coming from energy-efficiency as a resource for sustainability.

This brings about a number of difficulties, since the insertion of different kinds of qualitative aspects into a quantitative decision-making model is complex. It is easy to consider the costs saved per $\mathrm{kWh}$, but inserting aspects like "local community support is something more difficult to figure out" [4].

One alternative method for financial-only analysis is the Cost Benefit Analysis (CBA). The CBA is a tool that attempts to assign a monetary value to all non-economic aspects of a decision. The relation between the implement cost of a project and the benefit created by it is determined by the CBA. Although the CBA, in thesis, includes the net value of non-economic impacts as a monetary value, the "CBA can be used to produce almost any result desired by the analyst to suit his own prejudices or the interests of his sponsor, since the attempt to transform every potentially significant effect into a monetary value requires an arbitrary and subjective judgment on the part of the analyst" [5]. More recently [6] used the CBA to evaluate domestic energy-efficiency programs and was able to overcome the difficulties in order to reach monetary values for non-economic aspects, as mentioned by [5]. In this way [6] used the sensitivity analysis for costs to minimize impacts of inaccurate estimations and concluded "a perfect methodology for evaluating large-scale energy-efficiency programs is not yet available" [6]. To overcome the limitations of CBA analysis, [5] suggest, in their article, the use of a multi-dimensional approach and a way to deal with this issue using the analytical hierarchy process. It uses the concept of a decision tree with paired alternative comparisons.

\subsection{The Analytical Hierarchy Process Issue}

The analytic hierarchy process (AHP) is a powerful and flexible method used in decision-making that supports the determining of priorities. It also identifies the best option within a number of possible alternatives considering quantitative and qualitative aspects. Through the reduction of complex decisions to decisions that can be paired and compared (paired comparison), the AHP does not only help decision makers obtain the best option, but it also provides a clear view of why that alternative is the best. The AHP is executed in 3 phases: Structuring, Judgment and Synthesis of Results [7].

The AHP has already been used in multi-criteria decisions regarding energy conservation policies by [8] and [9], among other authors, but a common aspect among them is that traditional decision-making processes usually ignore non-monetary aspects. Reference [8] used the AHP to determine what the most effective policy instruments were for promoting energy conservation in Jordan and remembered that "the hierarchical structure of AHP allows the DM (Decision Maker) to break the complex decision problem down into smaller, but related, problems in the form of goals, criteria, sub-criteria, and alternatives".

Initially, it is necessary to establish the criteria and sub-criteria to be used in the evaluation as well as the alternatives. The next step is to organize these alternatives in a hierarchical manner, as shown in Figure 1. This organization can have as many levels as necessary. The top level must always be the goal to be attained and the bottom level must consist of the alternatives. The intermediate levels consist of the criteria, their respective subcriteria and, if necessary, other, lower, levels.

After the definition of the hierarchical tree, an evaluation within each level is started. This evaluation is normally carried out by comparing the pairs to each option at each level. However, it is also possible to evaluate them using absolute rates. A scale from 1 to 9 was arbitrated to compare the pairs, as proposed by [7]. This scale amplifies the distance and makes the most important choice (9) nine times more important than the choice of equal importance (1). If one were to use a 2 to 10 scale, for example, the most important choice (10) would only be five times more important than the choice of equal importance (2). Using more than 5 categories could complicate judgment, whereas less than 4 would impose limits on judgment and increase inconsistency. For this reason, 5 categories were adopted, where:

1 = equal importance;

3 = a little more important;

$5=$ more important;

$7=$ clearly or strongly more important;

$9=$ much more important.

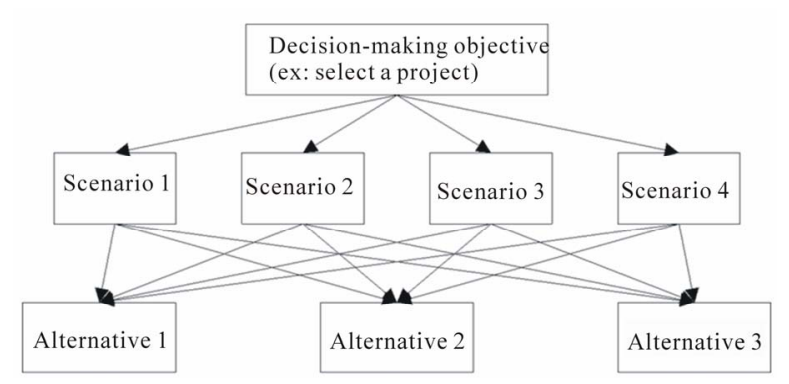

Figure 1. Hierarchical tree for the AHP methodology. 
The intermediate values can be used to clearly demonstrate the evaluation. Each alternative is compared with the rest using this scale. Upon finishing the evaluation, Equation (1) can be formulated, with the dimensions $\mathrm{n}$ by $\mathrm{n}$ for the $Z$ matrix, where $\mathrm{n}$ is the number of items to be compared.

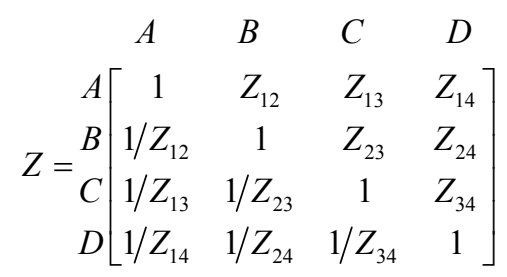

In Equation (1), the $Z_{i j}$ terms result from the paired comparison of items $i$ and $j$. The $Z_{i j}$ terms will always be equal to 1 when $i=j$ (similar to self-comparison alternatives), while $Z_{j i}$ is the inverse of $Z_{i j}$.

From this matrix, the priority vector (Vector $\mathrm{P}$ ) is found in this comparison. Then it is necessary to normalize the matrix from its columns, add the rows and divide the result by the number of elements in the row. The priority vector will be included in the comparison. When employing the AHP method, it is essential to verify data consistency.

Human beings are subjective by nature and this subjectivity means conflicting choices will sometimes be made. Such conflicts in the pairwise comparisons of the AHP method can be computed. This is possible by obtaining the Consistence Index $(C I)$. Mathematical methods are used to calculate this index through the maximum matrix autovalue $\left(\lambda_{\max }\right)$. The $C I$ can be calculated as follows:

$$
C I=\frac{\lambda_{\max }-n}{n-1}
$$

After calculating the $C I$, the consistency ratio $(C R)$ then needs to be calculated. The $C R$ is based on the comparison between the actual consistency index $(C I)$ and what the $C I$ would be if random choices had been made. In order to calculate the $C R$, it is necessary to use tables to provide a random index $(R I)$ for each dimension of the matrix, as shown in the Table 2 [7].

After finding the RI for the respective matrix dimension, the $C R$ is calculated using the ratio between $C I$ and $R I$. The $C I$ is used to check whether the judgments are consistent among themselves. This means that if one person makes random choices, or simply fails to clearly express his or her opinions in a consistent manner, there

Table 2. Random index for the matrix dimension.

\begin{tabular}{ccccccccccc}
\hline $\begin{array}{c}\text { Matrix } \\
\text { Dimension }\end{array}$ & 1 & 2 & 3 & 4 & 5 & 6 & 7 & 8 & 9 & 10 \\
Random Index & 0 & 0 & 0.58 & 0.90 & 1.12 & 1.24 & 1.32 & 1.41 & 1.45 & 1.49 \\
\hline
\end{tabular}

will be proximity between the $C I$ and the $R I$. The result can be considered significant for a $C R$ lower than, or equal to, 0.1 . If it is greater than 0.1 , the comparisons must be evaluated again in order to achieve acceptable consistency. After carrying out this process for the top criteria, the same process needs to be executed with lower-level criteria. This makes it possible to find the weight of the sub-criteria within the superior criteria. Once this procedure is complete for all sub-criteria, the alternatives can be analyzed within the bottom sub-criteria, based on the same method.

After finding the weights for each alternative within the bottom criteria, the general ranking can be constructed through the following steps:

1) Multiply the alternative priority within the sub-criteria by the sub-criteria priority;

2) Once step one has been executed for all the subcriteria of a certain level and its criteria/sub-criteria subordinates of the next superior level, add up the results. It is necessary to multiply the result by the weight of the criteria or sub-criteria of the next level;

3) Repeat step 2 at a superior level;

4) Repeat step 3 until the top level. Upon reaching this level, the value obtained will be the total priority of the alternative.

As steps above demonstrate, the AHP is an interactive method, where the number of comparisons grows rapidly in accordance with the number of criteria. As [10] warn, "a primary criticism of the Analytic Hierarchy Process (AHP), as originally presented by [7], is the number of comparisons required to develop the judgment matrices". For large AHP problems, the number of interactions needed may become a problem when solving the problem manually or using a spreadsheet. Reference [10] suggested a method to reduce the number of comparisons needed, but there are certain software packages that implement the AHP, such as the Expert Choice ${ }^{\mathbb{B}}$, Super Decisions and Decision Lens ${ }^{\mathrm{TM}}$, which minimize this problem with current computational capabilities. The user inputs the criteria, sub-criteria and alternatives into the software interface and the program assembles compareson sheets where the user is required to vote. After voting, the software automatically assembles the matrix, calculates the inconsistency index, the consistency ratio, the normalized weight and the ranking of alternatives. These packages also offer the possibility of using ratings or direct voting.

\subsection{Decision Making for Energy Efficiency Economics}

The criteria are sorted into two camps, economic and welfare-environmental. Each criteria has a few sub-criteria, such as IRR, NPV and risk for the economic criteria, as well as employee exposure, higher job creation 
and lowest environmental impacts for the welfare-environmental criteria. In the following example three alternatives are considered in the decision making:

- Alternative 1 is doing nothing;

- Alternative 2 is improving the current condenser system;

- Alternative 3 is installing a brand new condenser.

Attention must be drawn to the decision-making method and not to the values alone. The decision tree is shown in the Figure 2.

This decision tree simulates qualitative and quantitative aspects. The top-down analysis starts by attributing importance to the criteria. In other words, choosing which criteria is the most important: economic or welfare-environmental.

Within the sub-criteria qualitative analysis, Saaty's verbal scale is used to compare pairs: IRR with NPV, NPV with Risk, IRR with Risk, employee exposure with job creation, job creation with minimum environmental impacts and employee exposure with minimum environmental impacts.

The alternatives are classified according to each subcriteria. In this manner, there are some sub-criteria that must use quantitative grading and others that must use qualitative grading. The quantitative ones are IRR, NPV and job creation. The remaining ones are all qualitative.

Regarding qualitative sub-criteria, the alternatives are compared in pairs using the Saaty verbal scale [7]; meanwhile, the ratings concept is used in the quantitative subcriteria. It is a relation where, for each quantitative value, another value from 0 to 1 is attributed. For example, in the IRR sub-criteria, the rating can be defined starting from $11 \%$ to $100 \%$. In this manner, if any alternative has an IRR equal to $55 \%$, the grade will be exactly 0.5 .

The quantitative values do not need judgment, as they are numeric values, but the qualitative values do need judgment from specialists or the team involved in thedecision making, who in this case are those carrying out the work [4].

Specialist judgment infuses the decision with a subjective ingredient. The main difference for traditional

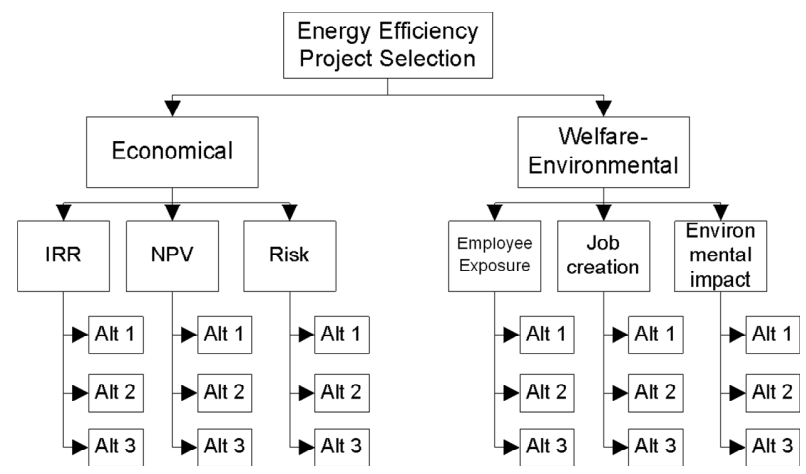

Figure 2. Decision tree for the example. subjectivism in the decision-making process is based on the fact that specialists are putting their experience to use in order to contribute to solving small issues, rather than the big decision. Using the AHP [11] analyzes the changes in the energy resources priority stack when replacing specialists with community members. Surprisingly, there were no significant changes in the priority list. Once the starting criteria are defined, the decision is much more sensitive to the criteria than to the judgments. Conversely, this particular case demonstrates only that the AHP study result is less sensitive to grading by specialists than to the definition of criteria.

In the following example, the weights of the economical and welfare-environmental criteria were changed and the response was automatically modified. By changing the weights as presented in the Table $\mathbf{3}$, the decision is changed to a new condenser installation project.

From the judgments of specialists, the software calculates all the priorities for each level, compared to the lower level. The software adds up the results and calculates the priority for each alternative. A table featuring the grading of the software response summary for each project alternative is presented below.

From Table 4, the project option with the best grade is to improve the current condenser. But if the decision maker wants to have a better understanding of the decision-building process, these software packages are able to perform a useful sensitivity analysis for each criteria. Accordingly, Figure 3 shows how each sub-criteria affects the decision.

\section{Conclusions}

A more deep analysis from the investor's perspective of energy-efficiency projects demonstrates the need to consider accountable details that will be a key factor in comparing projects fairly. The popular payback and IRR and NPV methods have deficiencies known to investors.

Table 3. Alternative decision change due to weight adjustment.

\begin{tabular}{cccc}
\hline Criteria & Economical & $\begin{array}{c}\text { Welfare } \\
\text { Environmental }\end{array}$ & $\begin{array}{c}\text { Alternative } \\
\text { suggestion }\end{array}$ \\
\hline $\begin{array}{c}\text { Original } \\
\text { weight } \\
\text { New } \\
\text { weight }\end{array}$ & $73.90 \%$ & $26.10 \%$ & Improvement \\
\hline
\end{tabular}

Table 4. Software response summary.

\begin{tabular}{ccc}
\hline Order & Alternative & Score \\
\hline 1 & $\begin{array}{c}\text { Alternative } 1 \text { is doing nothing } \\
\text { Alternative } 2 \text { is improving } \\
\text { the current condenser system } \\
\text { Alternative } 3 \text { is install a } \\
\text { brand new condenser }\end{array}$ & 0.650 \\
\hline
\end{tabular}




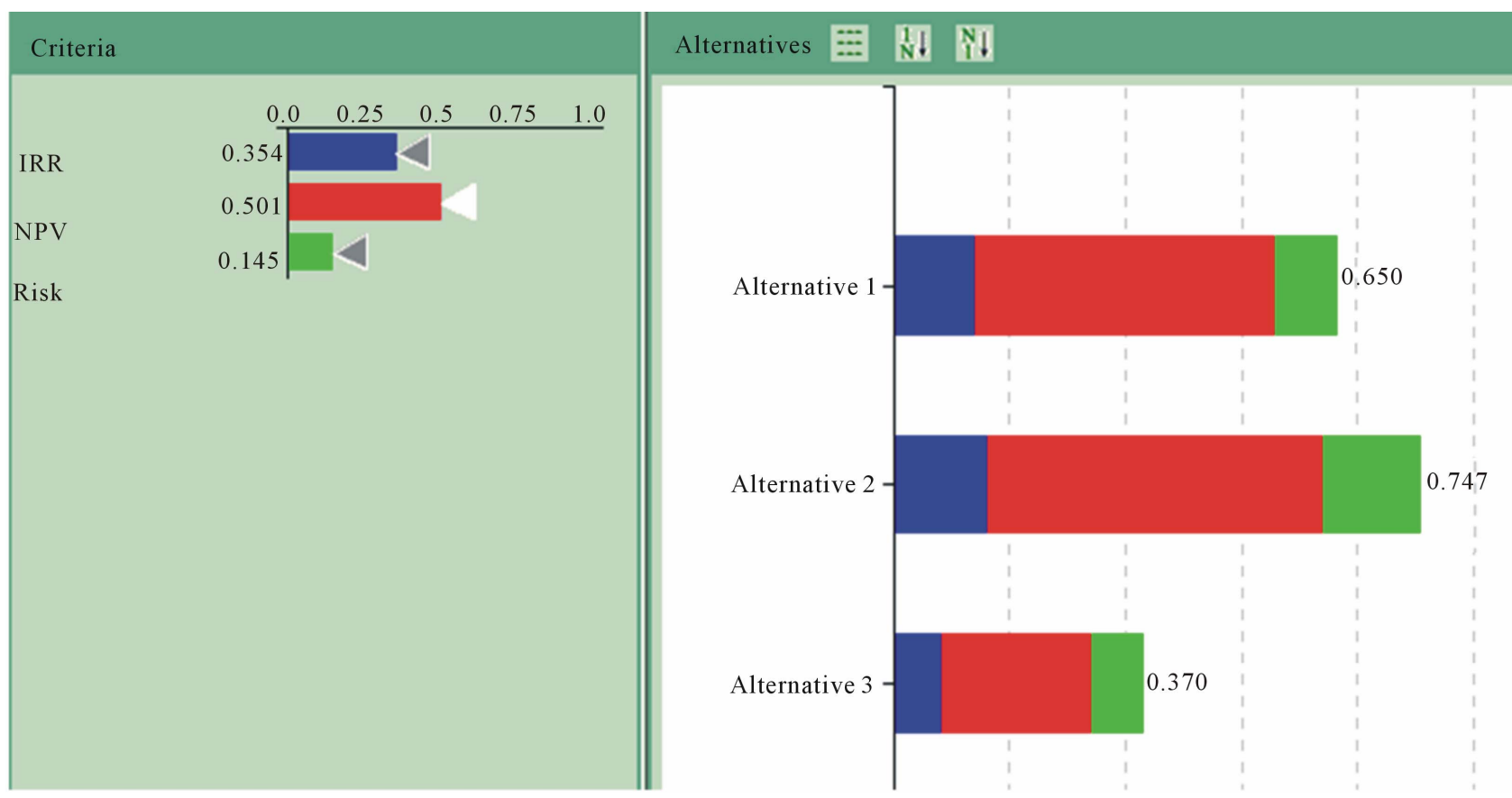

Figure 3. Economic sub-criteria sensitivity analysis.

However, they are useful if used with caution. The calculation of NPV from the cash flow savings versus expenses proved its inefficiency inasmuch as it does not bring out the actual value of the returns. In this case, it is necessary to consider depreciation and taxes. Apart from this, depreciation period is a determining factor to the investor return.

The addition of qualitative aspects in the decisionmaking is a very important factor when making a thorough and reliable evaluation. Non-economic factors are often not considered due to the lack of knowledge or even difficulty in bringing them to the decision agenda.

The AHP is an alternative method for solving problems pertaining to qualitative aspects in the decisionmaking process, particularly in energy-efficiency economics as energy planning tool. It is also helpful to support the often-ignored decision-making development process.

From the calculated quantitative aspects using wellknown methodologies such as NPV, IRR and Risk Evaluation, the AHP makes it possible to include qualitative aspects in the decision-making agenda in a standardized and repeatable manner.

Reference [5] warned about a significant limitation of CBA, AHP and other decision making methods. In the long term, they are limited to consider the interests of future generations since they transform qualitative aspects into a monetary value and execute the voting process or calculate the discount rates based on present insight.

Even though grading is able to affect the result of AHP project choices, according to [11], it is also possible to observe that the AHP study results are less sensitive to grading by specialists than to criteria definition.

From the practical standpoint, the AHP enables companies and decision-makers as whole to include qualitative aspects in the decision-making agenda that currently depend on the personal beliefs of managers. That is true even for the modern power system planning looking for sustainable development where the energy-efficiency economics inclusion is necessary.

\section{Ackknowledgements}

To the São Paulo Research Foundation-FAPESP (from the portuguese acronym "Fundação de Amparo à Pesquisa do Estado de São Paulo"), for the support given to the project "New Instruments for Regional Energy Planning Aiming at Sustainable Development of the western region of São Paulo" ("Novos Instrumentos de Planejamento Energético visando o Desenvolvimento Sustentável do Oeste Paulista”), code 03/06441-7.

\section{REFERENCES}

[1] C. E. M. Russell, "Strategic Industrial Energy Efficiency: Reduce Expenses, Build Revenues and Control Risk," Alliance to Save Energy Report 2003, Washington.

[2] F. Couto, "Agência Canal Energia, Negócios, 2007." http://www.canalenergia.com.br/

[3] O Estado de São Paulo, 2009. Carga tributária no Brasil bate recorde e chega a $35.8 \%$ do PIB.

http://www.estadao.com.br/noticias/economia,carga-tribut 
aria-no-brasil-bate-recorde-e-chega-a-35-8-do-pib,399074 , 0. htm

[4] M. E. M. Udaeta, "Planejamento Integrado de Recursos Energéticos para o Setor Elétrico-PIR (Pensando o Desenvolvimento Sustentado)," Tese de Doutorado, Escola Politécnica da Universidade de São Paulo, Brasil, 1997.

[5] D. Simpson and J. Walker, "Extending Cost-Benefit Analysis for Energy Investment Choices," Energy Policy, Vol. 15, No. 3, 1987, pp. 217-227. doi:10.1016/0301-4215(87)90083-8

[6] J. P. Clinch and J. D. Healy, "Cost-Benefit Analysis of Domestic Energy Efficiency," Energy Policy, Vol. 29, No. 2, 2001, pp. 113-124. doi:10.1016/S0301-4215(00)00110-5

[7] T. L. Saaty, "The Analytic Hierarchy Process: Planning, Priority Setting Resource Allocation," McGraw-Hill, London, 1980.

[8] M. M. Kablan, "Decision Support for Energy Conserva- tion Promotion: An Analytic Hierarchy Process Approach," Energy Policy, Vol. 32, No. 10, 2004, pp. 1151-1158. doi:10.1016/S0301-4215(03)00078-8

[9] P. Konidari and D. Mavrakis, "A Multi-Criteria Evaluation Method for Climate Change Mitigation Policy Instruments," Energy Policy, Vol. 35, No. 12, 2007, pp. 6235-6257. doi:10.1016/j.enpol.2007.07.007

[10] K. H. Lim and S. R. Swenseth, “An Iterative Procedure for Reducing Problem Size in Large Scale AHP Problems," European Journal of Operational Research, Vol. 67, No. 1, 1993, pp. 64-74. doi:10.1016/0377-2217(93)90322-E

[11] D. Cicone, "Modelagem e Aplicação da Avaliação de Custos Completos Através do Processo Analítico Hierárquico Dentro do Planejamento Integrado de Recursos," Dissertação de Mestrado, Escola Politécnica da Universidade de São Paulo, Brasil, 2008. 